\title{
GASOLINE-HYDROGEN OPERATED SI ENGINE AND ITS PERFORMANCE ANALYSIS
}

\author{
N.S.Gandhi ${ }^{1}$, A.V.Kulkarni ${ }^{2}$, R.S. Jahagirdar ${ }^{3}$, M.S.Sawade ${ }^{4}$ \\ ${ }^{1}$ Assistant Professor, Mechanical Engineering Department, SYCET, Maharashtra, India \\ ${ }^{2}$ Associate Professor, Mechanical Engineering Department, SYCET, Maharashtra, India \\ ${ }^{3}$ Principal, IOK College of Engineering, Pune, Maharashtra, India \\ ${ }^{4}$ Assistant Professor, Mechanical Engineering Department, SYCET, Maharashtra, India
}

\begin{abstract}
Fossil fuels like as coal, petroleum, natural gas meets the world's energy demand. They are depleting rapidly at the same time there combustion products are causing global problems such as acid rain, greenhouse effect, ozone layer depletion and pollution which is adversely impacting our environment and eventually total life on our planet. All researchers and engineers always struggling to produce a best suitable and reliable way for substitution of existing fossil fuels such as gasoline, diesel. Hydrogen gas has been considered as a best alternative to gasoline. The various investigators have completed their experiment by running various capacity engines on hydrogen. Most of such experimenter is successful in running IC engines on hydrogen without any big modification. There results and findings are available in the open literatures. However there is no consistency between the results of investigators and this is the big problem of these experiments. The hydrogen combustion increases thermal efficiency and its high velocity burning characteristic gives faster and smoother burning. The hydrogen also reduces critical pollution levels. Hydrogen combustion produces very clean exhaust due to its desirable characteristics. The hydrogen burning lowers HC, CO, $\mathrm{CO}_{2}$ and $\mathrm{NO}_{X}$ levels from exhaust. As of now hydrogen combustion is dangerous due to back fire problems, but new developed technologies and science in fire arresters ensures us the backfire free operation of hydrogen operating engine and same time make it possible to control hydrogen supply precisely. In this paper the experimental analysis and result discussion is made on performance and emissions behavior of hydrogen-gasoline fuelled SI engine and its safe use.
\end{abstract}

Keywords: SI Engine, Gasoline, Hydrogen, Thermal efficiency, Specific fuel consumption and Emissions

\section{INTRODUCTION}

The fossil fuels such as petroleum, natural gas and coal are being depleting rapidly. These fuels fulfill the energy demand. They are producing high levels of emissions which causing global pollution and environmental problems such as the greenhouse effect, acid rains, ozone layer depletion also by combusting them causes to hamper the natural environment and eventually entire life on our planet. Researchers, engineers and scientists always trying to develop new fuels and burning technologies which will able to lower the today's pollutions levels [1].

Now a day's hopes have again been raised about production and development in "hydrogen economy" sector because most of them agreed that hydrogen is best alternative fuel to replace the existing fossil fuels as hydrogen is having the clean burning characteristics. For an engine running only with hydrogen the exhaust gases doesn't contains carbon oxides, hydrocarbons, particles and lead compounds excluding the unburned hydrocarbons or the carbon oxides provided by oil burning inside the combustion chamber [2]. The hydrogen gas is acting as a light gaseous fuel. It is having high heating value on mass basis, wide flammability that gives wide mixture range in air which permits extremely lean or rich mixtures to support combustion. It requires lower amount of energy to start ignition process which results in extremely high speed flames. Its energy released by combustion per unit mass of chemically correct mixture remains high. The combustion properties of hydrogen have much influence on its performance as an engine fuel [4]. There are mainly two different ways available to introduce hydrogen in combustion chamber for burning process [5].

\subsection{Partial Hydrogen Substitution}

If hydrogen is used as supplementary fuel in SI engine then it results in improved engine performance. The experiments carried by various author's shows that the specific fuel consumption decreases while the engine thermal efficiency increases [6].

\subsection{Total Hydrogen Substitution}

Here the gasoline fuel supply is changed to hydrogen supply. By elimination of carburetor and supply of lean mixtures the back fire problem avoided which is very dangerous in case of hydrogen usages [6]. The supply of lean mixture reduces $\mathrm{NO}_{\mathrm{X}}$ level and specific fuel consumption. Any small existing SI engine on hydrogen there is no requirements of large modifications [7]. 


\section{SYSTEM FACILITIES}

The basic aim of this work is to modify the existing system of SI engine to incorporate hydrogen supply to it. These modifications should be smallest possible [3]. A medium capacity four cylinder, four strokes, water cooled, petrol engine is selected for experimental purposes. The specification of the engine are OHC ISUZU make SI engine, $1817 \mathrm{cc}$, four stroke, four in line cylinders, max torque 13.8 $\mathrm{kg}-\mathrm{m}$ at $3000 \mathrm{rpm}$ and water cooled. A flashback arrestor or flame arrestor is used which stops the flame from burning back up into the equipment and causing damage or explosions. This work is carried out in IC engine laboratory of Shreeyash College of Engineering and Technology, Aurangabad. All experiments carried out on day June 20, 2014 at night and timings from $22.00 \mathrm{hrs}$ to $1.30 \mathrm{hrs}$. This is because to achieve lower atmospheric temperature and low occupancy around laboratory as hydrogen is very explosive gas.

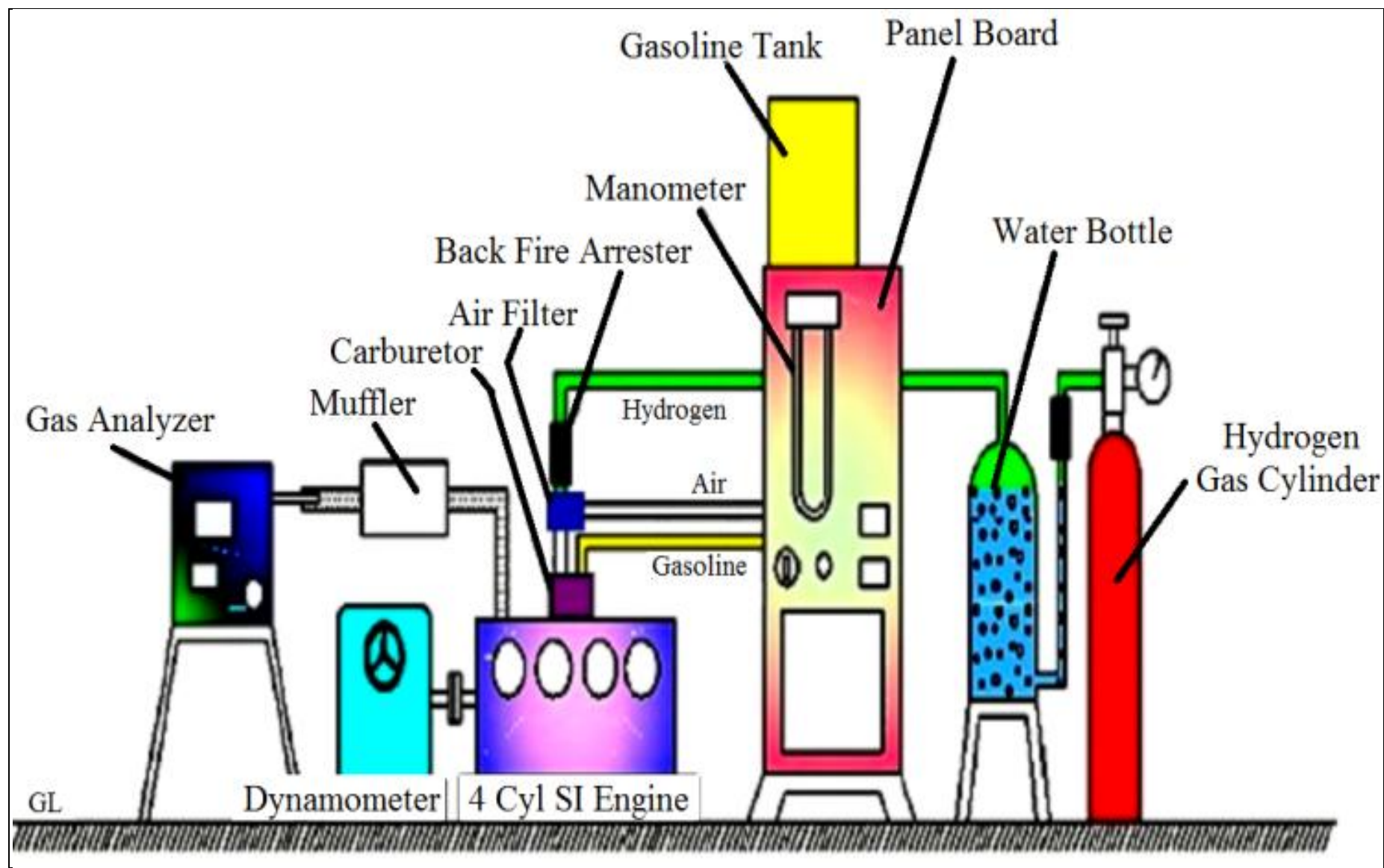

Fig -1: Experimentation facilities with proposed assembly of hydrogen cylinder and auxiliaries

\section{RESULTS AND DISCUSSION}

The various experimental results such as brake thermal efficiency, fuel consumption obtained for pure gasoline fuel supply and composition of gasoline with hydrogen mixture. All these results are formulated on graphs, due to which it becomes very easy to come to the discussion part rapidly. Just by looking at the performance figures, the various conclusions can be drawn easily. Following are the selected parameters and levels.

Table -1: Experimental Parameters and Levels

\begin{tabular}{|l|l|l|l|l|}
\hline Sr. No & Parameters & \multicolumn{3}{|l|}{ Levels } \\
\hline 1 & $\begin{array}{l}\text { Hydrogen Supply } \\
\text { (lpm) }\end{array}$ & 2 & 4 & 6 \\
\hline 2 & Load (kg) & 1 & 3 & 5 \\
\hline 3 & Speed (rpm) & 1200 & 1100 & 1000 \\
\hline
\end{tabular}

The data gathered from the experiment is targeted to convert in desired parameters such as brake thermal efficiency, specific fuel consumption with the help of standard relations. The emission behavior is drawn using exhaust gas analyzer. 


\subsection{Effect on Specific Fuel Consumption}

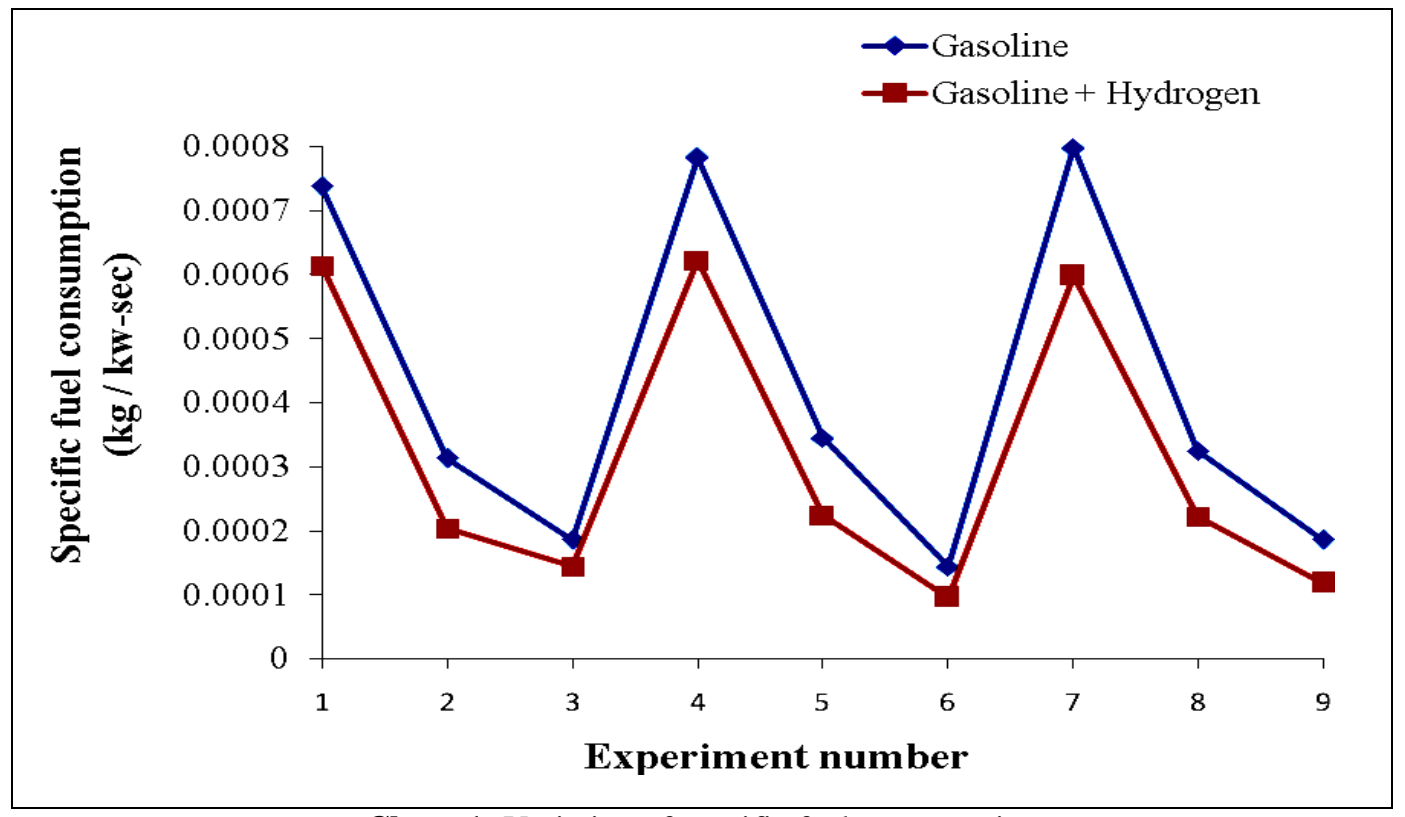

Chart-1: Variation of specific fuel consumption

From chart-1, it is found that specific fuel consumption with gasoline and hydrogen operation found to be decreases. It almost follows same nature of gasoline operating engine with lower values of specific fuel consumption. The reduction in specific fuel consumption is due to wide flammability of hydrogen gas, improvement of the combustion process and higher burning velocity. Specific fuel consumption is at the minimum value for high load, maximum speed and medium substitutions of hydrogen fuel in to gasoline fuel.

\subsection{Effect on Brake Thermal Efficiency}

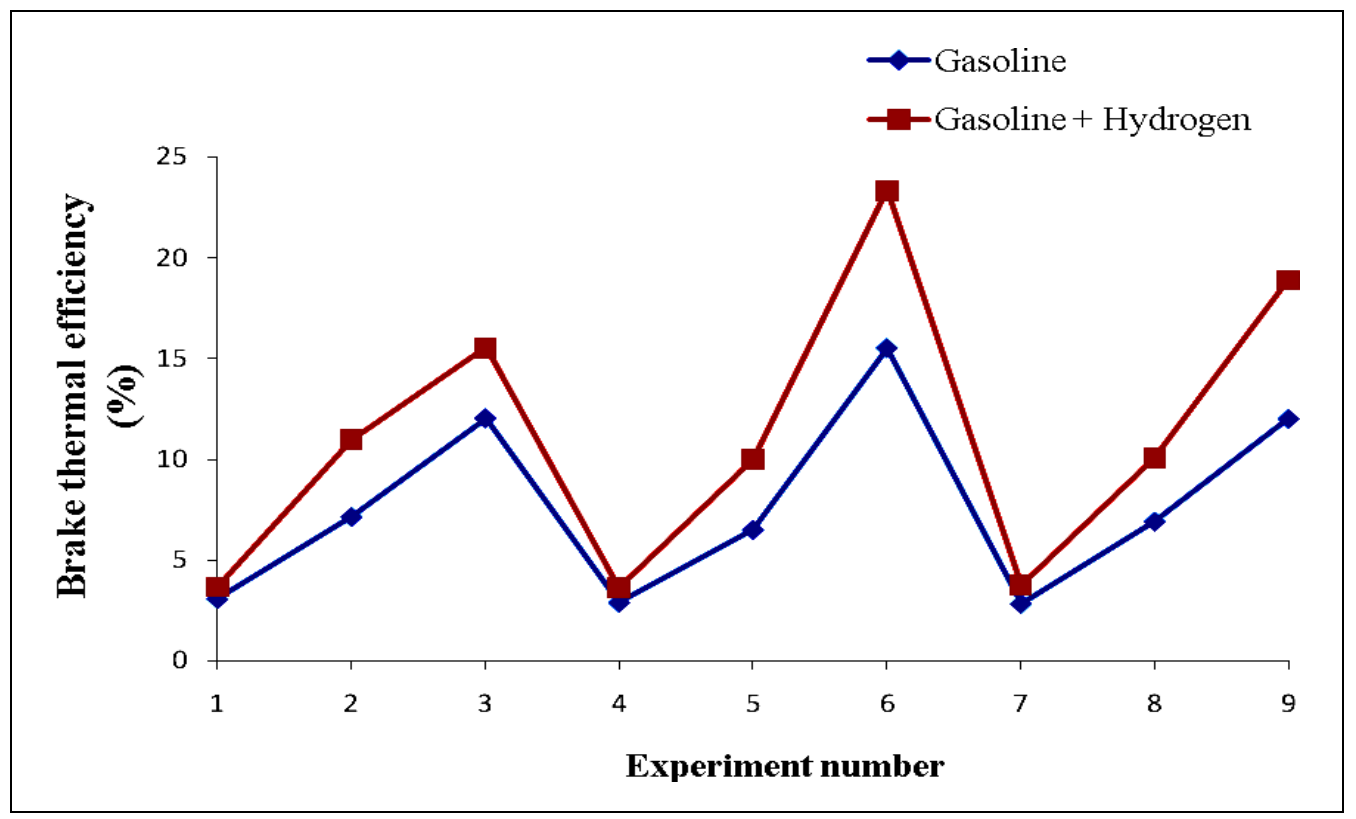

Chart-2: Variation of brake thermal efficiency

From chart-2, it is found that brake thermal efficiency with gasoline and hydrogen operation increases. At maximum speed and high loads deviation is more. Hence more brake thermal efficiency can be ensured at high speed and high loads with gasoline and hydrogen operation. Brake thermal efficiency is at the maximum value for high load, speed and medium substitutions of hydrogen fuel in to gasoline fuel. The wide flammability which is property of hydrogen permits hydrogen fueled engine to operate at lean and very lean mixtures and to obtain an improvement in brake thermal efficiency of the engine. The hydrogen properties which provide a high efficiency engine running at all load adjustments because of a much higher burning rate and lower ignition energy [7]. 


\subsection{Effect on CO Emissions}

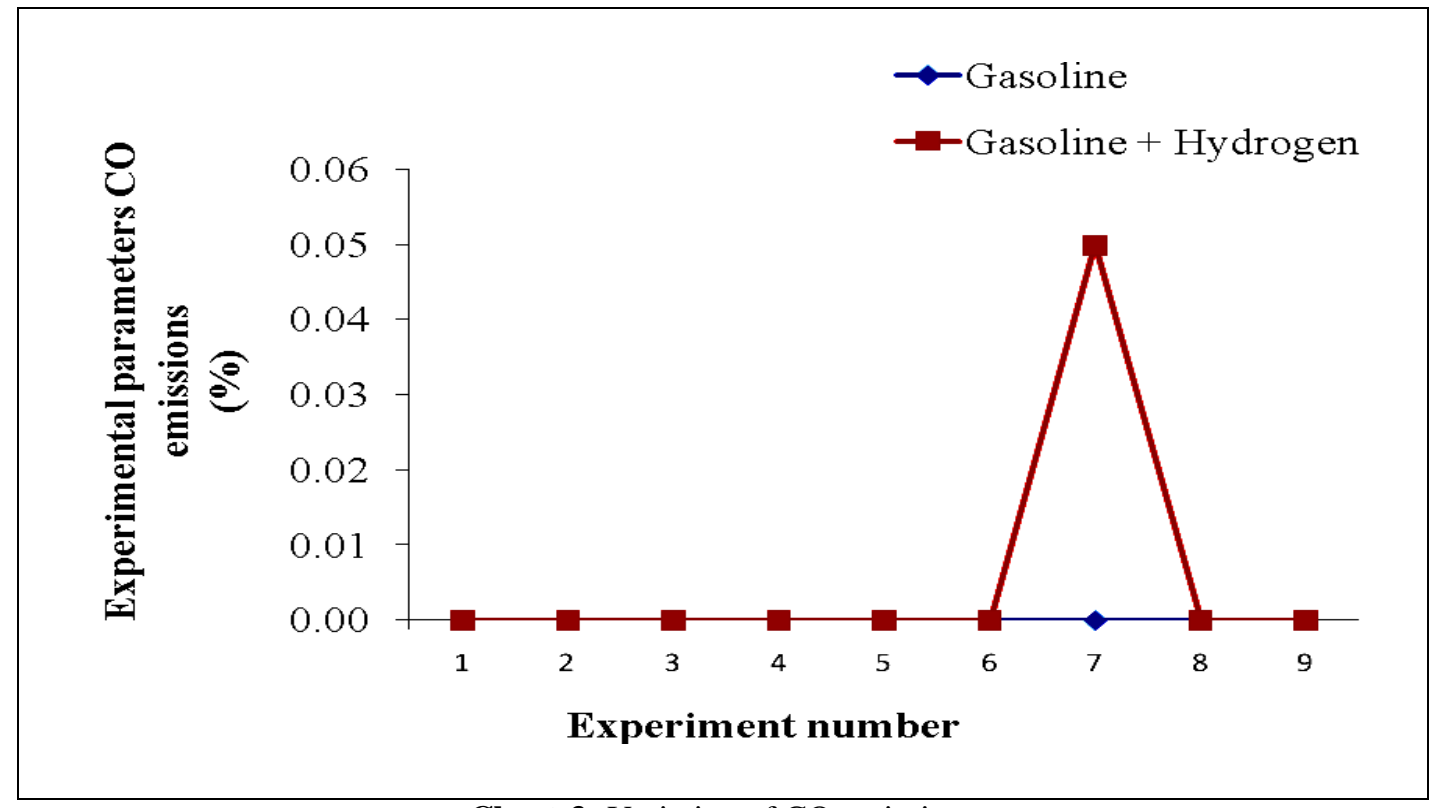

Chart-3: Variation of CO emissions

From Chart-3, during experimental parameters, CO emissions are almost zero for gasoline and hydrogen operating engine for all speed and loads conditions. It indicates addition of hydrogen does not impact inherently on $\mathrm{CO}$ emission levels. It is also found that during idling $\mathrm{CO}$ emissions are higher for gasoline and hydrogen operating engine than pure gasoline fuel supply. As hydrogen flow rate increases say beyond $5 \mathrm{lpm}$, the $\mathrm{CO}$ emission level decreases. During Idling, $\mathrm{CO}$ emissions are higher for gasoline and hydrogen operating engine than pure gasoline fuel supply for low flow rates of hydrogen. If the hydrogen flow rate increases the $\mathrm{CO}$ emission level decreases. Although excess air for complete combustion is present in the cylinder, the engine is not capable of burning the total fuel. It was expected that hydrogen fueled engine must have zero CO emission. Some amount of $\mathrm{CO}$ is still present. This is due to the burning of lubricating oil film inside the engine cylinder. As engine speed and $\mathrm{H}_{2}$ supply increases, $\mathrm{CO}$ emission tends to decreases [8].

\subsection{Effect on $\mathrm{CO}_{2}$ Emissions}

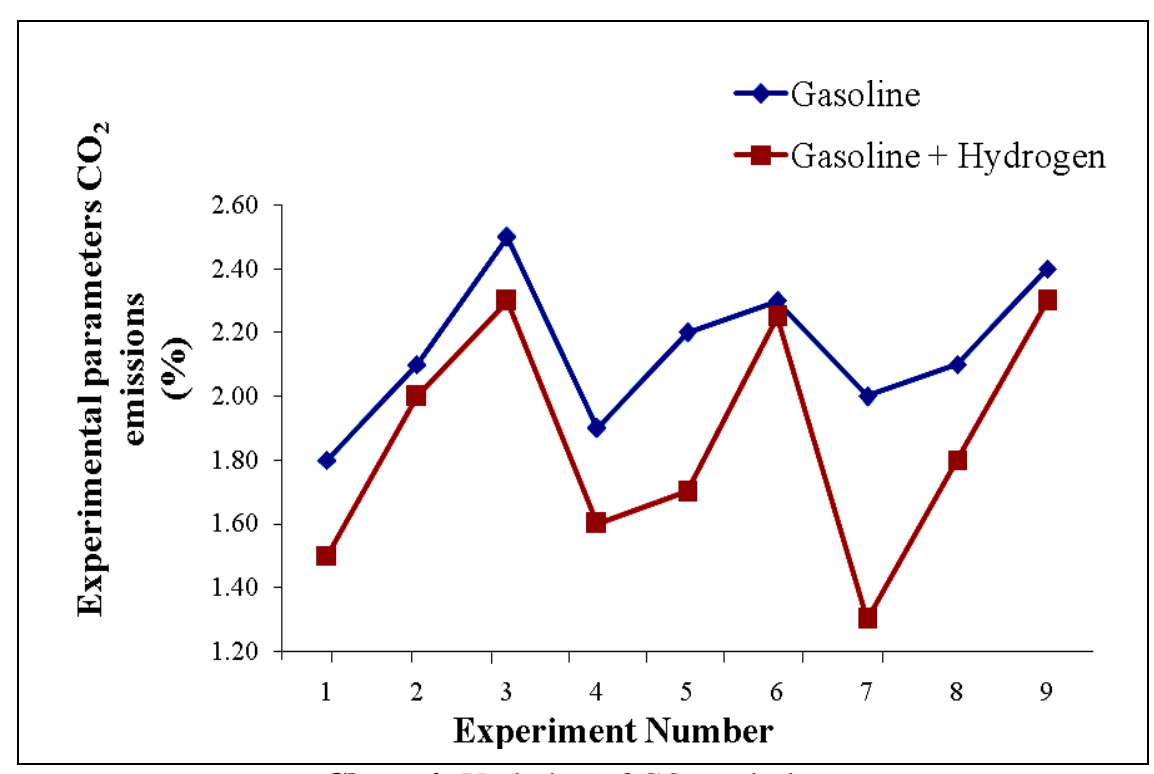

Chart-4: Variation of $\mathrm{CO}_{2}$ emissions

From chart-4, during experimental parameters, $\mathrm{CO}_{2}$ emissions are lower for gasoline and hydrogen fuel operating engine than pure gasoline supply. At low engine loads and lower engine speed $\mathrm{CO}_{2}$ emissions significantly decreases. $\mathrm{CO}_{2}$ is non-toxic but contributes to the greenhouse effect. $\mathrm{CO}$ and $\mathrm{CO}_{2}$ emissions are not expected from the combustion of pure hydrogen. As engine lubrication oil film sticks onto the cylinder wall and burn with the air-hydrogen mixture, it can account for these traces of carbon emissions. 


\subsection{Effect on HC Emissions}

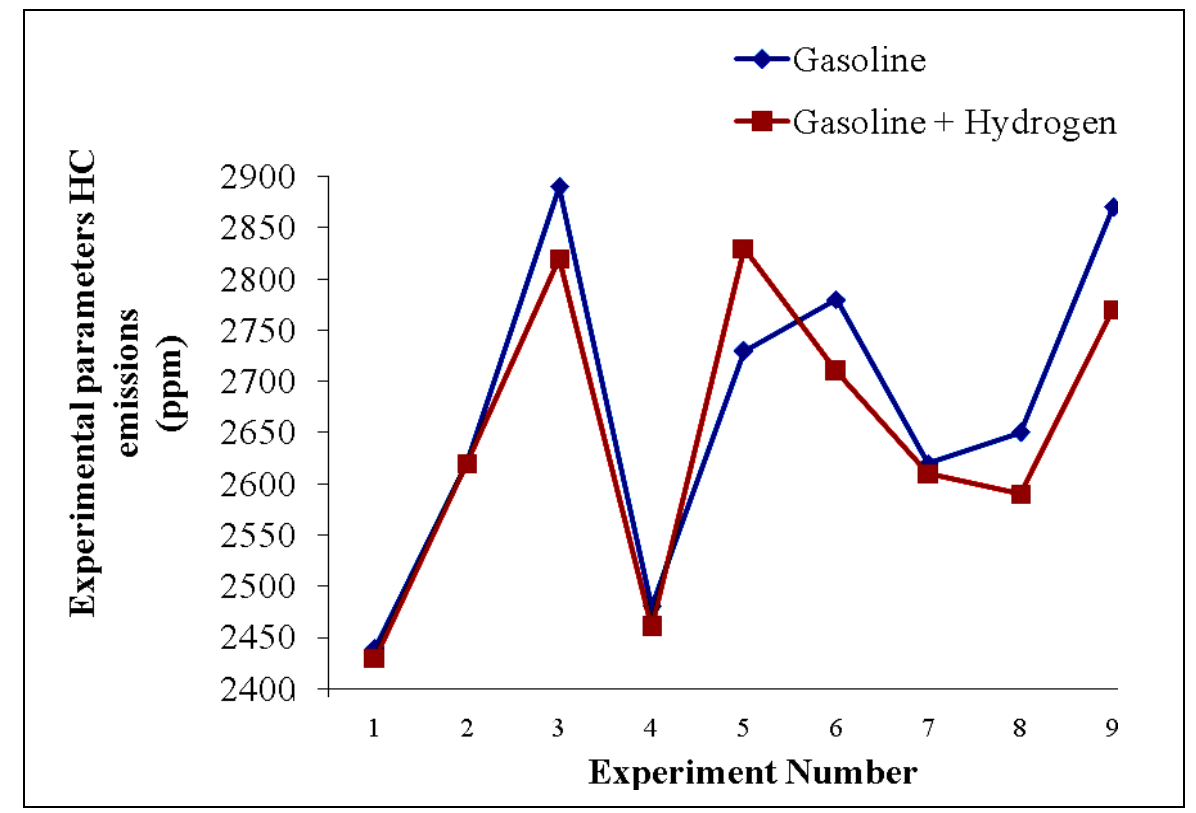

Chart-5: Variation of $\mathrm{HC}$ emissions

From chart-5, during experimental parameters, HC emissions are found lowered for gasoline and hydrogen operating engine than pure gasoline supply. At high loads and high speed $\mathrm{HC}$ emissions significantly decreases. At low engine loads and lower engine speed HC emissions significantly decreases. At very lean mixtures usage, the combustion duration increases, engine efficiency decreases causes to the combustion instability and $\mathrm{HC}$ in exhausts gases appear [8].

\subsection{The Regression Equation}

Experimental data is used to develop a relation between hydrogen gas flow rate, load and speed. Regression analysis is used for this purpose. This Regression equation obtained is as follows which may also termed as mathematical corelation between three selected parameters.

$$
B_{\text {th }}=-15.8+0.214 \mathrm{H}_{2}+3.90 \mathrm{Load}+0.0130 \text { Speed }
$$

The following are the optimum parameter and levels obtained. The hydrogen fuel flow $4 \mathrm{lpm}$, load $5 \mathrm{~kg}$ and speed $1200 \mathrm{rpm}$. Setting of these values on experimental setup will give highest possible brake thermal efficiency with lower values of emissions. By substituting above values in regression equation, the theoretical brake thermal efficiency equal to $20.15 \%$. Hence to verify these values a trail is taken known as confirmation test.

\subsection{Confirmatory Test}

After selecting the optimal levels, the final step is to verify the results using the optimum design parameter levels in comparison with standard engine parameters with combination of gasoline and hydrogen fuel. Practically the brake thermal efficiency closes to $19.64 \%$.

\section{CONCLUSION}

The preliminary experiments carried out were described as earlier and a regression analysis was carried to determine patterns in the data and obtain optimal points for the response factors. It was then attempted to verify these findings in the next set of experiments. The findings for each response factor are listed below.

- $\quad$ Brake specific fuel consumption is at the minimum value for high load, speed and maximum substitutions of hydrogen fuel in to gasoline fuel. Brake specific fuel consumption decreases with addition of hydrogen gas.

- Brake thermal efficiency is at the maximum value for high load, speed and moderate substitutions of hydrogen fuel in to gasoline fuel. It means that the use of hydrogen as an additive can give more efficient engine operation. As load increased, efficiency increased, which means the engine has high efficiency with the increase in load.

- During experimental parameters, CO emissions are almost zero for gasoline and hydrogen operating engine for all speed and loads conditions. The $\mathrm{CO}_{2}$ emissions are lower for gasoline and hydrogen fuel operating engine than pure gasoline supply. At low engine loads and lower engine speed HC emissions significantly decreases. The HC emissions are found lowered for gasoline and hydrogen operating engine than pure gasoline supply. At high loads and high speed HC emissions significantly decreases.

- Hydrogen supply system used offers great flexibility in operation to establish the engine adjustments.

- It is beneficial to add more content of hydrogen at idling to reduce $\mathrm{CO}$ losses and then at running conditions it should be adjusted as per load and speed as per requirement. 
- The data shows that the fuel consumption rate decreases with more additives, which means that the emission reduction can be achieved by adding $\mathrm{H}_{2}$ leading to more complete combustion.

- At high speed of the engine with supply of hydrogen engine runs very smoother with lower vibrations.

- During heavy accelerations maximizing torque output is the main goal and in case of addition of $\mathrm{H}_{2}$ quick heavy acceleration is possible because of faster burning characteristics of hydrogen and gaseous phase of hydrogen, as gases burns very faster than liquid fuel.

- The test results showed that the significant improvements in fuel consumption and $\mathrm{CO}, \mathrm{CO}_{2}$ and $\mathrm{HC}$ emissions can be obtained when combined hydrogen and gasoline as fuel is used in the engines with carburetor. This does not necessitate major modifications such as fuel injection system, electronic ignition system and exhaust control system which increase cost of engine.

- Hydrogen has very high diffusivity. This ability to disperse in air is considerably greater than gasoline and is advantageous for two main reasons. Firstly, it facilitates the formation of a uniform mixture of fuel and air. Secondly, if a hydrogen leak develops, the hydrogen disperses rapidly. Thus, unsafe conditions can either be avoided or minimized.

\section{SCOPE FOR FUTURE STUDY}

- One of the main hindrances with running higher substitution proportions in the engine was due to concerns over the capability of the engine to withstand the high pressures and pressure created due to higher flow rates of hydrogen substitution.

- If for experimental purposes, an engine could reinforced with separate valve arrangement for hydrogen and gasoline mixture injection directly in to the cylinder, it would be extremely interesting to see the effects on brake thermal efficiency and emissions at higher substitution percentages.

- Varying the percentage of hydrogen flow rates and observing its effects on $\mathrm{B}_{\mathrm{th}}$ and $\mathrm{NO}_{\mathrm{X}}$ emissions would make an interesting study.

- Changing the mixture quality by hydrogen substitution also place of substitution during the course of the experiments would give remarkable results.

- An engine on a dynamometer does not perfectly parallel an engine on a vehicle. Firstly, an engine on a vehicle has several accessory loads that are not present on an engine on a dynamometer. Secondly, all of the conditions in a test cell including temperature and pressure are closely. A vehicle encounters temperatures and precipitation that cannot be simulated in a test cell. The cooling system on vehicle also cannot be simulated in a test cell. An engine is cooled by air flow through a radiator and directly by air flow over the engine and power train system. Lastly the dynamics of a transmission system are not present.

\section{REFERENCES}

[1]. N. Negurescu, C. Pana, M. G. Popa and A. Cernat, Performance comparison between hydrogen and gasoline fuelled spark ignition engine, Thermal Science, Volume 15, No. 4, pp 1155-1164, 2011.

[2]. K. Gillingham, Hydrogen Internal Combustion Engine Vehicles: A Prudent Intermediate Step or a Step in the Wrong Direction?, Global Climate and Energy Project, Jan. 2007.

[3]. N. Negurescu, C. Pana and A. Cernat. Aspects of using hydrogen in SI engine, U.P.B. Sci. Bull, Series D, Volume 74, Iss. 1, pp 11-21, 2012.

[4]. M. Kosar, B. Ozdalyan and M. B. Celik, The usage of hydrogen for improving emission and fuel consumption in a small gasoline engine, Journal of Thermal Science and Technology, pp 101-108, 31 Feb 2011.

[5]. F. Yuksel and M.A. Ceviz, Thermal balance of a four stroke SI engine operating on hydrogen as a supplementary fuel, web site- www.elsevier.com/locate/ energy, pp 10691080, 15 March 2002.

[6]. B.R. Prasath, E. Leelakrishnan, N. Lokesh, H. Suriyan, E. G. Prakash and O. M. Ahmed. Hydrogen Operated Internal Combustion Engines - A New Generation Fuel. Website: www.ijetae.com, ISSN 2250-2459, Volume 2, Issue 4, pp 52-57, April 2012.

[7]. R. Sierens and S. Verhelst, Hydrogen Fuelled Internal Combustion Engines. Commission of the European Union, BRST-CT98-5349.

[8]. R. Mahtani, Investigating The Use of Hydrogen As an Alternative Fuel. Project Number: AEE-HV09, 29 April 2010.

\section{BIOGRAPHIES}

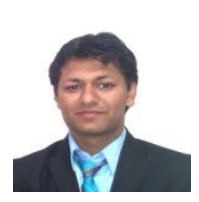

Mr. N. S. Gandhi born in Maharashtra, India in 1988. He is B.E. (Mechanical) from Maharashtra Institute of Technology, and ME (Heat Power). Future studies and interest in Renewable Energy field.

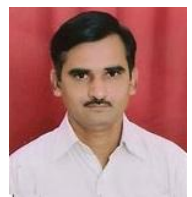

Mr. A. V. Kulkarni born in Maharashtra, India in Currently he is working as Principal at Shreeyash College of Engineering, Aurangabad. He is pursuing Phd and interest in Renewable Energy field.

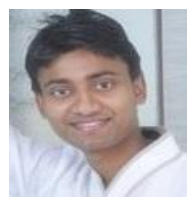

Mr. M. S. Sawade born in Maharashtra, India, persuing M.E. from Sinhgad Academy of Engineering, Pune 